\title{
Saúde e mídia na construção da obesidade e do corpo perfeito
}

\author{
Health and media in construction of obesity \\ and perfect body
}

Giane Moliari Amaral Serra 1

Elizabeth M oreira dos Santos 2

\footnotetext{
1 Departamento de Nutrição em Saúde Pública da Universidade do Rio de Janeiro/Unirio. Av. Pasteur, 296/3o andar, fundos, 22290-240, Rio de Janeiro RJ. gimol@terra.com.br 2 Departamento de Endemias Samuel Pessoa/Escola Nacional de Saúde Pública/Fiocruz
}

\begin{abstract}
This text presents the results of a study aimed to address the discourses on obesity control published in the magazine Capricho. Through the analyses of discourses, the "diets" for loosening weight published in this adolescents driven magazine were analyzed contrasting the technical-scientific contents to those media framed. Result shows that there is a struggle between the health technical discourse and the media discursive construction. The media hybrid text that includes several symbolic fields and meanings (technical-scientific and audience related) is framed with ambiguities. This might contribute more to the marketing of light products or a life style and body than to an adequate and nutritional education for the adolescents.

Key words Control obesity, Media, Nutritional education, Health political
\end{abstract}

Resumo $O$ artigo apresenta o caminho e conclusões de uma pesquisa desenvolvida na ENSP/Fiocruz, como parte do curso de mestrado, sobre a relação entre o adolescente e a obesidade como construção simbólica e discursiva na revista Capricho. Utilizando a metodologia da análise do discurso e considerando os debates sobre o tema no campo, enfatizamos as tensões e paradigmas que envolvem a midia, os profissionais de saúde e o receptor que pretende modificar uma situação estética e sociossanitária que o aflige. Observamos que a obesidade é transformada em tema de disputa entre profissionais médico-sanitários e profissionais midiáticos se constituindo em parte das lutas que envolvem diversos campos científicos, simbólicos e sociais.

Palavras-chave Obesidade, Adolescente, Produção de sentidos, Recepção, Políticas de saúde 


\section{Considerações iniciais}

0 adolescente é uma construção social moderna, que significa a possibilidade da emergência de subjetividade e novas referências e padrões identitários. Biologicamente é a fase de maior velocidade do crescimento do indivíduo, o que implica uma necessidade de maior aporte calórico e de nutrientes (Gambardella, 1999). Admite-se que nem sempre nessa fase da vida são respeitadas as demandas que compõem essa "faixa" social e cronológica. Sabe-se, entre nutricionistas e profissionais de saúde, que nessa idade, 0 aumento do aporte calórico pode se dar pelo excesso de alimentos ricos em gorduras e açúcares, como no caso da prática alimentar dos lanches rápidos, levando a sobrepeso, obesidade e doen ças carenciais. Ao contrário, pode haver uma diminuição do aporte calórico, pois, o adolescente também é levado a se preocupar ou está muito preocupado com sua imagem corporal e acaba "cedendo" à estética corporal atual, que privilegia o corpo esguio e esbelto, o que poderá ter como conseqüência o desenvolvimento de transtornos alimentares, como: anorexia e bulimia nervosa.

Os meios de comunicação veiculam ou produzem notícias, representações e expectativas nos indivíduos com propagandas, informações e noticiário em que de um lado estimulam o uso de produtos dietéticos e práticas alimentares para emagrecimento e, de outro, instigam ao consumo de lanches tipo fast food. $N$ ão se trata de uma decisão ou ação das empresas midiáticas, elas integram um contexto empresarial e um sistema de crenças em que há uma estreita relação entre uma suposta verdade biomédica e um desejo social e individual. 0 corpo é um campo de luta que envolve diferentes saberes, práticas e imaginário social.

O objetivo principal desta análise é a compreensão das estratégias discursivas adotadas pela mídia quanto às práticas alimentares de emagrecimento. 0 estudo centrou-se na produção dos sentidos e significados desses discursos, procurando identificar como os saberes encontram-se no espaço midiático de forma a contribuir para a construção do senso comum. Este estudo tem a perspectiva de contribuir para ampliar e aprofundar a discussão sobre a influência da mídia na formação de novos hábitos alimentares; contribuir para o atendimento de saúde mais integrado ao universo do adolescente; subsidiar a implementação de políticas públicas que visem regular a publicidade de alimentos, fiscalizar a produção de novos produtos al imentícios e seus rótulos.

\section{Caminhos percorridos}

Este estudo é de natureza qual itativa, descritiva e exploratória. Tomamos como objeto de análise a revista Capricho. Tal escolha justifica-se, por ser esta, segundo o Instituto Verificador de Circulação (IVC/RIO, 1998), a revista de maior abrangência direcionada ao público adolescente. Capricho tem periodicidade quinzenal e está no mercado desde 1952, portanto já tem uma identidade no mercado da mídia impressa.

Foram analisados 25 números da revista de todos os meses do ano de 1999, sendo selecionadas 16 revistas com matérias ligadas à temática. Explica-se o recorte temporal pelo fato de a década de 1990 caracterizar-se como a de expansão de consumo de alimentos dietéticos no Brasil. De acordo com a Associação dos Produtores de Alimentos dietéticos (ABIAD), em 1990, os fabricantes juntos faturaram $160 \mathrm{mi}$ Ihões de dólares com a venda de alimentos de baixa caloria. A receita de 1997 foi de 840 miIhões de dólares (Veja, 1998).

A revista tem 120 páginas distribuídas em cinco seções, cada uma com cerca de 15 páginas. Entre as cinco seções, a de "saúde e beleza" é a que insere a temática a ser investigada. N ela aparecem depoimentos de artistas famosos e suas recomendações para se manter com saúde e com o corpo esteticamente perfeito.

A maioria das matérias encontra-se sob a forma de entrevistas. 0 repórter faz perguntas e ouve respostas sobre fatos ocorridos ou sobre atos, opiniões e idéias do entrevistado.

\section{Quem é o leitor da revista Capricho?}

Por intermédio de correspondência pessoal sobre dados do Instituto Marplan (Castells, 1999), foi possível caracterizar o perfil do público leitor da revista Capricho, tomando-se por base um consolidado realizado em 1998, que incluiu as seguintes regiões metropolitanas: São Paulo, Rio de Janeiro, Belo Horizonte, Porto Alegre, Recife, Salvador, Curitiba, Brasília e Fortaleza - observa-se que são as meninas entre 10 e 15 anos que mais lêem a revista. Pe los critérios do Instituto $M$ arplan essas meninas pertencem às classes socioeconômicas $\mathrm{A} e$ $B$, isto é, meninas de classe média alta. 


\section{Metodologia adotada}

A abordagem metodológica privilegiada éa análise de discurso (AD). A AD francesa acredita que quem produz os discursos não tem uma autonomia sobre sua fala, pois esta é determinada por convenções e interesses político-ideológicos. A AD anglo-americana acredita na força e autonomia de quem produz a fala, portanto as relações entre contexto e discurso são limitadas. Pinto (1999) destaca que o desenvolvimento teórico relativo à contextualização das marcas formais encontradas na superfície textual, bem como o reconhecimento de que todo evento de comunicação é ou faz parte de um ritual social cujas convenções deve seguir e que a contextual ização passa sempre por mediações, conciliam ambas as correntes.

Apoiamo-nos na AD defendida por Pinto (1999), que considera produtos culturais, textos e/ou outros sistemas semióticos, como imagens, padrões gráficos, no interior de práticas sociais contextualizadas histórica e socialmente. A análise depende do contexto descritivo, explicativo e crítico, e também de avaliação da eficácia do processo comunicativo imediato.

Para a coleta de dados das matérias elaborou-se uma grade analítica considerando: o título da matéria, quem fala, o que fala, quem é o intermediário, qual (is) o(s) modo(s) de dizer do discurso e o que converge e o que diverge entre o discurso midiático e o discurso técnicocientífico.

Os títulos das matérias da revista Capricho foram incluídos porque, segundo Gouazé (apud Lopes, 1998), funcionam como uma propaganda, chamam a atenção, apresentam as questões que motivam a leitura e qualificam a informação. Os títulos da imprensa, graças ao próprio processo de figuração, constituem um verdadeiro texto dentro do texto, fazem, ao mesmo tempo, mostrar e esconder o texto para o qual dirigem o olhar do leitor.

Quanto ao segundo item da grade - quem fala - , destaca-se que, dependendo de quem fala, o discurso pode adquirir maior ou menor legitimidade, estabelecendo ou não identificação com o leitor. 0 discurso é o espaço em que o saber e o poder se articulam, pois quem fala, fala de algum lugar e com base em um direito reconhecido institucionalmente (Braga, 1999).

0 terceiro item - o que fala - se refere ao que é dito. Permite observar os significados e sentidos explícitos e/ ou implícitos nos discur- sos sobre práticas al imentares para emagrecimento num determinado contexto.

No quarto item - quem é o intermediário - , ressal ta-se que normalmente tal intermediação acontece valendo-se dos repórteres do veículo midiático. Segundo Benveniste (1989), o locutor, ao apropriar-se do aparelho formal da língua, enuncia sua posição por índices específicos. Quando trata da posição do locutor, o autor levanta a questão da relação que se estabelece entre o locutor e seu enunciado e o mundo, onde a posição sócio-histórica do enunciador ocupará um espaço fundamental. Conseqüentemente, não existe uma neutralidade de quem enuncia, pois enuncia de acordo com a filosofia do véculo para qual desempenha suas funções. 0 veículo por sua vez, em geral, encontrase vinculado aos interesses de seus patrocinadores.

0 quinto item - qual(is) o(s) modo(s) de dizer do discurso - trata de como o discurso se mostra, interage e seduz. Pinto (1999) assume que a produção de um texto utiliza a linguagem verbal e outros sistemas semióticos (como imagens) para cumprir as três funções básicas (mostração, interação e sedução). A primeira constrói o referente ou o universo de discurso do qual o texto fala, a segunda estabelece os vínculos socioculturais necessários para se dirigir ao interlocutor, e a terceira distribui "afetividade" positiva e negativa. Essas funções se real izam de modo integrado, sendo apenas didática a separação entre elas.

Ainda na grade, encontramos como último item, o que converge e o que diverge entre o discurso midiático e o discurso técnico-científico em relação aos hábitos alimentares em geral e, especificamente, às práticas al imentares para emagrecimento. Este item nos permite mostrar a correlação de forças que age entre o que é dito pela mídia e o que é dito pela ciência da nutrição. Para identificar a tipologia do discurso midiático sobre "práticas alimentares de emagrecimento" foram criadas variáveis definidoras dos discursos, de modo a distinguir o conteúdo técnico-científico do conteúdo socioestético. No conteúdo técnico-científico, as variáveis privilegiadas de análise consistem em consumo e gasto. No conteúdo socioestético, a ênfase será dada às variáveis estéticas: beleza, boa forma e sucesso.

Consideramos, em nossa análise, que na AD o analista empresta atenção especial à elaboração dos textos, quer quanto ao uso da linguagem verbal, quer quanto ao uso de outras 
semióticas. É na superfície dos textos, em que podem ser encontradas as pistas ou marcas deixadas pelos processos sociais de produção de sentidos, que 0 analista vai interpretar. Por mais que existam normas, parâmetros, critérios para tal interpretação, está presente um enorme viés de julgamento e visão crítica do analista. Na produção da notícia diversos elementos técnicos e estéticos, interesses de diferentes naturezas e profissionais são envolvidos. Entre o ponto de partida - a idéia - e 0 artigo consumido pelos leitores diferentes mediações são realizadas.

\section{Análise e discussão dos resultados}

0 poder da atual mídia caracteriza-se como poder de produzir sentidos, projetá-los e legitimá-los, dando visibilidade aos fenômenos que conseguiram, em primeiro lugar, atrair os jornalistas. Portanto, a função do repórter não se esgota em estar entre o acontecido e o público. Ele seleciona, enfatiza, interfere por meio de palavras e imagens na construção simbólica dos acontecimentos.

Certamente, esse processo encontra resistências e modifica-se ao longo da produção e veiculação do noticiado. D evemos considerar que a recepção não élinear e homogênea.

Os títulos e subtítul os ( $Q$ uadro 1 ) se referem ao discurso do repórter, ou seja, quem faz a intermediação entre o veículo e o público leitor.

Para exemplificar a análise e discussão dos títulos e subtítulos identificando também o papel da intermediação escolhemos dois exemplos encontrados nas matérias da revista $\mathrm{Ca}$ pricho.

O primeiro título analisado é: “Em forma de diversão - Aí vai um empurrãozinho para você levantar da cadeira de praia e se mexer. São sete sugestões para manter a forma e queimar calorias enquanto você brinca e toma sol" (revista Capricho, 17 de janeiro de 1999). 0 enunciado "em forma" é destacado pela cor e tipo de letra, o que vem mostrar que o grafismo e o cromatismo são estratégias importantes para marcar significados, cujo discurso quer passar. Encontra-se em maiúscula, na cor azul contrastando com a cor preta do resto do subtítulo em tamanho comum, exceto pela expressão "são sete sugestões para manter a forma e queimar calorias" que também encontra-se em azul.
0 título da matéria associa gasto energético e perda de peso, num roteiro em que o aspecto mágico e lúdico está presente. 0 cenário seduz o indivíduo para fazer dieta, principalmente, aquele que tem dificuldade em seguir tais regimes. 0 enunciado também nos remete à idéia de corpo esteticamente perfeito quando coloca, no início, a expressão "Em forma", e leva a leitora a crer que estando em forma, estará bonita. Para reforçar tal estratégia de sedução coloca uma expressão de compensação, a saber: "queima calorias enquanto brinca e toma sol".

0 enunciado não apresenta categorias discursivas como artigos, ou pronomes, pois o título refere-se a um estado de coisas, a uma ação. 0 título principal não utiliza verbo, cumprea função de fragmentação do enunciado e faz com que o leitor se insira nos interstícios da frase de modo a completar seu sentido. Extraímos da matéria a intermediação do repórter para enfatizar o sentido dado pelo título: "Brincar na água" é a chamada número um das sete sugestões da matéria. 0 intermediário diz: Pular onda, mergulhar e nadar no mar - tudo isso gasta energia. Dá para perder de 150 a 200 calorias em 30 minutos (revista Capricho, 17 de janeiro de 1999).

A última expressão "Dá para perder de 150 a 200 calorias em 30 minutos" demarca um discurso técnico-científico. Aparece destacada em negrito, e todas as outras sete sugestões acompanham o mesmo estilo. 0 curioso, porém, é que não aparece qual quer esclarecimento por parte de um especialista, ou seja, trata-se de um discurso mediado pelo repórter.

Para ilustrar a análise, outro dado interessante ao lado de cada sugestão, a imagem de uma modelo fazendo exercício. De uma forma sutil, ao lado de cada texto, aparece escrito de baixo para cima, em letras pequenas, o nome ( marca/grife) da roupa que a modelo está usando.

Outro exemplo bastante interessante de título que se utiliza estrategicamente do discurso técnico-científico é: "Pega leve - as dúvidas mais comuns que a gente tem sobre dieta e peso" (revista Capricho, 25 de abril de 1999). 0 título "Pega leve" de matéria de seis páginas encontra-se em destaque pela cor e tamanho de letra. A palavra "pega" apresenta-se na cor preta e em letra bastão e a palavra "leve", em vermelho na letra bastão com tamanho maior que a primeira.

0 discurso refere-se diretamente à temática dieta e evoca certa legitimidade, ou melhor, 
Quadro 1

Títulos das matérias da revista Capricho em 1999

\begin{tabular}{lll}
\hline Data & Título & Subtítulo \\
\hline $17 / 1$ & $\begin{array}{l}\text { Em forma de diversão. Aí vai um empurrãozinho } \\
\text { para você se levantar da cadeira de praia e se mexer }\end{array}$ & $\begin{array}{l}\text { São sete sugestões para manter a forma e queimar } \\
\text { calorias enquanto você brinca e toma sol }\end{array}$ \\
$31 / 1$ & Pura feitiçaria & A Tiazinha não está mais sozinha. Joana Prado, \\
& & $\begin{array}{l}\text { a feiticeira do H, éa nova atração do programa } \\
\text { de Luciano Huck. Nós conversamos com ela }\end{array}$
\end{tabular}

28/2 Toalhas quentes...

$14 / 3 \quad$ Sem multa. A gente sempre reclama de al gumas coisas do nosso corpo, do tamanho do quadril, dos seios, da altura... E alguns tipos de roupas não ficam mesmo legais em todo mundo. M as não se preocupe: existem jeitos de esconder seus pontos fracos e valorizar suas qualidades

25/4 Pega leve - as dúvidas mais comuns que a gente tem sobre dieta e peso

23/5 A coxinha é a rainha. Qual o seu lanche preferido na escola? Durante um mês, fizemos essa pergunta a várias meninas do país. A coxinha foi a preferência nacional

$6 / 6$

Oba! Namorar queima calorias

20/6 Dieta de gente fina. 0 médico de Danielle Winitts, Alessandra N egrini e Camila Pitanga faz um cardápio para você emagrecer até dois quilos por semana

Na minha geladeira tem... Será que a geladeira dos famosos é diferente da nossa? Luciano, Netinho, Sheyla M ello, Sâmara Felippo e Thierry Figueira mostram pra gente o quenão falta na deles

Sanduíche dos sonhos. Todo mundo tem o seu. Já pensou juntar todos eles num só? Foi o que fizemos, a partir das receitas de al guns artistas. Eles inventaram mesmo para criar um sanduíche ideal. Uma nutricionista comenta a indicação de cada um

12/9 A vencedora é... Do dia 13 ao dia 22 de agosto 32 meninas participaram de um concurso nacional de modelos. Depois de muita entrevista, regime e choradeira, só três chegaram lá

Um show de programa. 0 programa físico da Eliana mudou radicalmente seu corpo

Dieta da fome. Sabe o que é uma pessoa subnutrida? É alguém que come bem menos calorias do que deveria para se manter em pé. É o caso de um monte de modelos se assume como gordinha e planeja viajar a Nova York para seguir carreira de modelo de perder peso - e não ganhar denovo depois é comendo

Me acho sexy e descobri que os homens também acham, graças a Deus 
confere um "tom" científico à matéria. Ao mencionar as dúvidas acerca de dietas e peso, a mídia recorre a discursos de especialistas, certificados, para responder a tais indagações. Esses especialistas têm o poder da ciência em relação a quem o escuta, já que cabe ao técnico reproduzir seus conhecimentos e aos leigos, escutar e absorvêlos. 0 título "Pega leve" - leva-nos a crer que quem faz dieta é uma pessoa leve, uma pessoa light, uma pessoa-luz que reúne os atributos de uma sociedade em que o brilho e a velocidade são qualificadores essenciais. 0 título também faz uma referência à gíria "pega leve", ou seja, à idéia de que fazer dieta não é nenhum sacrifício, é algo fácil, leve, possível. Esses são significados que estão diretamente relacionados ao padrão estético de magreza/leveza e ao estilo de vida que um indivíduo contemporâneo deve assumir.

Os sujeitos das 16 matérias analisadas, quem fala, são variados. M édicos e artistas aparecem em seis matérias cada, o que pode nos sugerir que tanto o discurso dos médicos como o dos artistas assumem o valor de verdade. Outros sujeitos são os professores de educação física e os nutricionistas, profissionais com quatro participações. Vale destacar a participação dos nutricionistas no universo das dezenove matérias que versam sobre temática diretamente ligada a prática desse profissional.

Observamos também a participação de adolescentes e de psicólogo. No caso dos adolescentes, a participação do psicólogo não é surpreendente. Essa é uma excelente estratégia para criar vínculos de identificação com o público leitor. O bserva-se que apesar de estar se falando sobre comportamento alimentar, em que aspectos sociais, culturais e psicológicos estão envolvidos, o psicólogo só aparece em uma matéria.

Em relação ao item da grade "o que é falado e como o discurso se mostra, interage e seduz 0 público leitor", podemos destacar que a característica distintiva do discurso midiático é o fato de 0 âmbito da sua legitimidade não ser delimitado pelas fronteiras de um domínio restrito da experiência. 0 repórter se apropria de diversos discursos de outrem e o reelabora numa linguagem mais geral para o público leitor. Portanto, o âmbito da legitimidade do discurso midiático é transversal ao conjunto de todos os domínios da experiência moderna (Porto, 1997).

O discurso científico tem seu âmbito de legitimidade restrito a um dos domínios espe- cíficos da sua experiência. Os discursos dos médicos, por exemplo, muitas vezes, somente são compreendidos pelos próprios médicos. A apropriação e a nova tradução por parte do discurso midiático de alguns aspectos dos saberes de outras áreas, especificamente da ciência, tendem a dar naturalidade às pretensões legítimas construídas historicamente pelos atores autorizados desses saberes. A mídia "dilui" o poder do discurso técnico-científico, ela se ancora na ciência como uma instância cultural significativa, com uma abrangência totalizante, pois a ciência, como destacaram Focault (1999) eBraga (1999), é essencialmente discurso etem pretensão da verdade.

Nas matérias analisadas os discursos dos especialistas, ou seja, os discursos técnicos-científicos, se mostram pelo poder da ciência em produzir certezas e verdades. Quanto à interação, esses discursos, por meio de seus interlocutores, criam vínculos socioculturais com o público leitor disponibilizando seu conhecimento científico e introjetando a idéia de homem saudável, equilibrado, controlado e racional. Perpassam a idéia de controle da saúdedoença em uma expectativa de vida eterna, isto é, a fantasia do controle da morte.

Cumprindo uma função de sedução e legitimação, o discurso técnico-científico trabaIha a concepção de moral do certo e errado, premiando os que acertam e seguem à risca os mandamentos da ciência e culpando os que erram e não os seguem.

Os sentidos e significados mais encontrados nos discursos dos especialistas são: autonomia/controle: Em relação ao IMC: você mesma pode calcular e ver se o seu peso está ou não comprometendo sua estética e sua saúde (médico - revista Capricho, 25 de abril de 1999). Nesse exemplo chamamos a atenção para a maneira como o especialista transfere para a cliente/paciente a responsabilidade de autocontrole. Ele, o especialista, não deixa de se apoiar em um instrumento científico (o Índice de M assa Corporal/IM C) para que a paciente se convença da necessidade e da sua própria capacidade de se auto-vigiar. 0 autocontrole funciona, ao mesmo tempo, como sedução para o paciente que julga estar tornando-se independente. É também uma forma de o especialista transferir a responsabilidade para o paciente. Portanto, se ele não seguir bem as orientações torna-se culpado pelo seu próprio insucesso.

Quando o enunciador é representado por um artista, não basta só a "fala", é primordial a 
sua imagem corporal, que passa a ser o discurso propriamente dito. A imagem que 0 artista transmite de estilo de vida ideal, perfeita, cria a interação com o público, ao mesmo tempo em que a imagem também seduz através do desejo que desperta nas pessoas de mimetizar artistas famosos e bem-sucedidos. 0 universo do discurso é o meio artístico/imagético, lugar reconhecido pelos indivíduos como lugar da fama, do sucesso, econômico e social. Esses discursos podem ser caracterizados como discursos socioestéticos, pois a sua força está na imagem.

Os discursos socioestéticos criam vínculos socioculturais com os leitores valendo-se da concepção de que "tudo posso", do homem/ imagem perfeita. Os discursos compõem e recriam a cultura individualista e subjetiva do final do século 20. Apregoam a autonomia do indivíduo, a praticidade, a rapidez/eficiência, a ação, e também as escolhas, significados e sentidos encontrados nos discursos dos artistas.

D estacamos alguns exemplos: autonomia/ poder: Faço meu próprio sanduíche quando estou com fome (Rodrigo Faro, revista Capricho, 29 de agosto de 1999). Neste exemplo, o verbo "fazer" é utilizado na primeira pessoa, acompanhado do pronome "meu". Ficam, assim, demarcados os sentidos de autonomia e poder, que são significados presentes nos discursos do tipo socioestético, ratificando os valores culturais da individualidade e da independência. Autocontrole/razão: Dieta é dieta, mesmo assim o médico libera duas refeições a cada semana. Isso quer dizer que você pode comer o que quiser com bom senso no almoço de sábado e no domingo, por exemplo (D anielle Winitts, revista Capricho, 20 de junho de 1999). Este é um exemplo de discurso que ressalta o papel da dieta como prescrição, pois a atriz parece falar não de uma refeição, mas de um remédio. Na expressão "o médico libera duas refeições a cada semana" o discurso demarca o sentido de dieta como restrição alimentar negociada no plano da interação entre o especialista e o sujeito do controle.

Em relação aos vínculos socioculturais estabelecidos com o leitor, observamos a racionalidade, ou seja, o indivíduo tem de ter consciência e responsabilidade para escolher o que vai comer. É uma forma de autocontrole, trata do indivíduo como dono de sua própria vida e saúde. Essa lógica exalta a individualidade. A sedução se manifesta com base na autonomia, mas vigiada e controlada pelo especialista.

O utro exemplo refere-se à autonomia/praticidade: Faço em casa sempre (o sanduíche). É prático e uma delícia (Suzana Werner, revista Capricho, 15 de agosto de 1999). Podemos observar que como os exemplos anteriores, este se refere ao mesmo universo (imagético). A função sedutora subjacente ao discurso é a praticidade; as pessoas necessitam ganhar tempo, a vida acontece de forma rápida e a alimentação tem de acompanhar adequando-se ao novo tempo.

Por último, um exemplo que se refere à escolha/ação : ... foi quando decidi agir. Mudei a alimentação e percebi que, sem ginástica, não havia milagre (matéria realizada com a apresentadora Eliana, revista Capricho, 26 de setembro de 1999). Este discurso mostra-se de acordo com o mundo imagético do sucesso. Interage e seduz o leitor pela idéia de que você pode e deve decidir sua própria alimentação e saúde. Relaciona sentido de controle e verdade científica sobre o equilíbrio entre consumo e gasto. 0 relato da apresentadora deixa explicitado que para se ter sucesso, no caso, com o corpo, deve-se escolher uma alimentação racional, seguir uma rotina de exercícios. É a escolha, ação e a razão.

Quando o enunciador é adolescente, além de ter seu corpo divulgado na matéria, fala para iguais e, conseqüentemente, seu discurso é reconhecido pelo grupo social e faixa etária. 0 referente e/ou universo do discurso é o próprio momento da adolescência, em termos gerais, uma fase em que os indivíduos se identificam bastante, pois vivem dilemas, anseios, angústias e desejos parecidos. Os discursos dos adolescentes apresentam formações discursivas dos dois tipos: técnico-científico e socioestético (imagético).

A mídia remete 0 adolescente a vivenciar um dilema. 0 veículo que estimula a prática do fast food, via publicidade, aproveitando-se da imagem de pessoas famosas para divulgação dessa prática, utiliza também discursos de especialistas que não indicam e nem concordam, sob o ponto de vista da saúde do adolescente, com o consumo desses produtos. $M$ ais grave: na veiculação desses produtos estão sendo divulgados e construídos modelos e padrões de beleza e de estética corporal não condizentes com as práticas al imentares que os profissionais de saúde apontam como saudáveis ou desejáveis. 0 que fazer? Consumir um modus vivendi descontraído, moderno, uma alimentação prática, rápida que você mesmo pode preparar, ou manter-se em forma com um corpo esteticamente perfeito? 
Diante do dilema, o adolescente torna-se indeciso e expressa-se como um sujeito ambíguo, vacilante, inseguro. Suas falas explicitam ambigüidade en tre cuidado, flexibilidade e radicalismo: Agora, estou tentando comer mais certo, porque vi que não adianta nada ser radical (revista Capricho, 19 de dezembro de 1999). Quando encano que engordei, simplesmente paro de comer comida. Troco tudo por salgadinhos, biscoitos, essas bobagens. Ou dou uma maneirada durante a semana e me acabo no fim de semana: como brigadeiro, tudo que vejo pela frente (revista Capricho, 19 de dezembro de 1999).

Esses exemplos ilustram o impasse em que os adolescentes se encontram diante da escolha de um padrão alimentar. 0 adolescente diz que não adianta ser radical com a alimentação e que deve comer de forma correta, mas também assume práticas al imentares radicais e incorretas do ponto de vista nutricional, pois precisa, a qualquer custo, conquistar o padrão ideal. Nos exemplos, podemos observar formações discursivas que se referem à técnica como as que se referem ao senso comum.

Nos discursos ricos em tensões e contradições encontramos também o sentido de competição, como no exemplo: O mercado é muito competitivo, se eu comer o chocolate hoje, vou dar chance para outra passar na minha frente (revista Capricho, 24 de outubro de 1999), referindo-se à seleção para modelo. $\mathrm{A}$ ideologia do poder e do sucesso está permeando as falas dos adolescentes. Quem não consegue competir no mercado é considerado um indivíduo fracassado.

Em relação ao sentido de controle, verificamos em algumas falas como: (...) tem bolo de chocolate uma vez por semana, mas com controle (revista Capricho, 26 de setembro de 1999); Todo dia me peso na balança que fica no meu quarto e também meço minha cintura e meu bumbum com a fita métrica que fica escondida no meu armário (revista Capricho, 19 de dezembro de 1999). Adolescentes se privam do prazer de comer para conquistar um determinado padrão estético. Paradoxalmente, ao mesmo tempo que adquiriram a liberdade em mostrar os seus corpos, mais se aprisionam em critérios estéticos, pois para desnudá-lo é necessário ter a forma padrão ideal.

Há um grupo em que meninas fazem detudo para se controlar e não engordar e por isso são consideradas vitoriosas; há um outro grupo em que as adolescentes que não conseguem fazer a dieta para manter o peso ou emagrecer são caracterizadas como as fracassadas, as que não farão sucesso e quiçá serão aceitas socialmente, é o que percebemos nos exemplos: Não consigo resistir mesmo sabendo que engorda; Minha mãe cozinha bem e eu não resisto às tortas que ela faz (revista Capricho, 23 de maio de 1999).

As dificuldades vividas pelas adolescentes podem ser compreendidas à luz dos aspectos que determinam as práticas e hábitos alimentares. As práticas e hábitos alimentares são determinados por aspectos sociais, psicológicos, culturais, econômicos e subjetivos. Alimentarsenão éapenas um ato biológico é também um ato de prazer (Rotenberg, 1999).

0 sentido de dieta para essas adolescentes caracteriza-se como o de restrição/proibição, o que não as motiva levando à não-manutenção. A dieta concebida dessa forma não considera a falta de tempo das pessoas, o gosto e as preferências, a relação de afeto que mostra 0 ato de preparar ou consumir um prato gostoso. Nesses casos temos o in sucesso. Esse sentimento, muitas vezes, leva 0 adolescente a experimentar métodos fáceis e rápidos para emagrecimento, mas que não garantem a adoção de um comportamento alimentar que promova a saúde, como podemos observar: Eu tomava um remédio para diminuir o apetite antes de ir às festinhas. Só que não adiantava muito e eu comia do mesmo jeito (revista Capricho, 29 de agosto de 1999).

Outros sentimentos como dúvidas, medo, sofrimento e insatisfação e culpa estão presentes nos discursos dos adolescentes. Esses sentimentos são suscitados nos adolescentes em função da hegemonia do corpo esbelto e esguio padronizado por valores culturais e mercadológicos.

Todos os indivíduos necessitam de informações, particularmente os adolescentes. Eles reclamam orientações, o que verificamos nos exemplos abaixo: Devo substituir tudo o que puder por alimentos diet e light? (revista Capricho, 25 de abril de 1999); Eu era muito gorda e, por isso, morro de medo de engordar de novo. Sou encanada com regime (revista Capricho de 29 de agosto de 1999); (...) mas sofria, tomava remédios que me deixavam deprimida, conta ela...; Quando comia me sentia culpada e ia correndo para a academia (revista Capricho, 21 de novembro de 1999).

Quanto à convergência e à divergência entre o discurso midiático e o discurso técnicocientífico, podemos afirmar que muitas moda- 
lidades discursivas das matérias sobre dieta/alimentação divulgadas na revista Capricho não traduzem nem expressam uma lógica ou procedimento teórico-metodológico admitido como válido no campo da nutrição, e muito menos promovem uma mudança qualitativa no comportamento alimentar. 0 que se vê, muitas vezes, são receitas "milagrosas" para emagrecimento, divulgadas por personalidades famosas. Tais mensagens suscitam no consumidor o desejo de experimentar tais "dietas" que prometem perda de peso rápida e saúde perfeita.

Selecionamos discursos sobre práticas alimentares para emagrecimento que evidenciam divergências com o que é preconizado pela ciência da nutrição. Por exemplo: troco tudo por tablete de chocolate; cortou tudo que adorava comer (revista Capricho, 4 de julho de 1999); Nossa dieta não tem base calórica, mas nutricional. Com 350 calorias/dia come-se de tudo, inclusive massa (revista Capricho, 24 de outubro de 1999).

A ciência da nutrição destaca que todo indivíduo deve ter uma alimentação saudável e equilibrada, tanto em quantidade como em qualidade. Devem ser feitas de quatro a seis refeições diárias, sendo duas grandes refeições (almoço ejantar) equatro pequenas (desjejum, colação, lanche e ceia). Essas refeições devem totalizar um aporte calórico diário ideal ao indivíduo, levando-se em consideração sua altura, seu peso e sua atividade física. Portanto, é necessário individualizar a dieta alimentar, até porque, como sabemos, não comemos somente para satisfazer as necessidades fisiológicas e biológicas, mas também as necessidades psicológicas, afetivas, sociais e culturais.

Para garantir o equilíbrio e 0 aporte de todos os nutrientes necessários a uma boa nutrição considera-se que deva estar presente em todas as refeições pelo menos um alimento de cada grupo de alimentos, a saber: grupo dos construtores (proteínas), grupo dos reguladores (minerais e vitaminas) e o grupo dos energéticos (carboidratos e gorduras). O utro princípio importante na ciência da nutrição éconsumir o que se vai gastar, ou seja, dieta equilibrada implica também prática de exercícios físicos.

A afirmação de que "dieta de 350 calorias diárias não tem base calórica" é verdadeira, mas esclarecer que esta dieta tem base nutricional é uma declaração falsa. A ciência da nutrição considera que uma dieta abaixo de 1.000 calo- rias/dia mostra-se insuficiente relativamente à quantidade de calorias e em termos nutricionais, especialmente, no caso de um adolescente que necessita de um bom aporte calórico e nutricional que garanta seu pleno desenvolvimento.

Em relação às privações a que se submetem as adolescentes em seus relatos nos discursos da revista Capricho, podemos afirmar que estas ferem frontalmente o princípio básico da nutrição que é o equilíbrio alimentar.

O utros exemplos de discursos divergentes à ciência da nutrição se referem ao uso de produtos dietéticos e medicamentos para emagrecer: ... um mês antes de uma viagem a Porto Seguro só comia bolacha de água e sal e tomava suco diet. Cheguei até tomar um remédio que reduz o apetite (revista Capricho, 29 de agosto de 1999); Faz mal substituir o açúcar comum por adoçantes? Não. Mas prefira os de aspartame ou de stévia que são naturais (revista Capricho, 25 de abril de 1999).

Segundo pesquisa realizada por uma subcomissão do Centro Brasileiro de Informações sobre D rogas Psicotrópicas (CEBRID/M inistério da Saúde), o consumo de medicamentos tipo anfetaminas no Brasil sal tou de 7,7 toneladas em 1988 para 23,6 toneladas em 1992 (dados divulgados no jornal Folha de S. Paulo, 20/4/94, p., 4). Os medicamentos para emagrecimento utilizam anfetaminas e ansiolíticos e são substâncias que provocam dependência. 0 uso desses fármacos está associado a alterações das funções cardíacas e da função renal; a distúrbios hormonais, sobretudo os da tireóide, além de distúrbios gástricos e neurológicos.

O uso de produtos dietéticos como sinônimo de produtos que garantem a saúde é questionável pela ciência da nutrição. Os nutricionistas orientam o uso desses produtos somente em dietas especiais, ou seja, para diabéticos e grandes obesos. Para redução de calorias existem outros métodos, como: redução do uso e melhor escolha do tipo de gordura para cocção e redução da quantidade de carboidratos, entre outros.

O utro achado importante, que do ponto de vista da ciência da nutrição não deve ser tomado como conduta própria no atendimento ao indivíduo, é a padronização da dieta que deve ser individualizada, particularizada. D estacamos al guns exemplos: Faço duas horas de musculação todos os dias na academia (revista $\mathrm{Ca}$ pricho, janeiro de 1999); O médico de Danielle Winitts, Alessandra Negrini, Camila Pitanga faz 
um cardápio para você emagrecer até 2 quilos por semana (revista Capricho, outubro de 1999).

No primeiro exemplo, o discurso da revista, ao divulgar que a modelo Joana Prado faz duas horas por dia de musculação, sugere que para ficar em forma, como ela, deve-se também fazer duas horas de musculação por dia, e sabemos que, em muitos casos, especialmente, para os adolescentes, não é um procedimento recomendado. Junto com a carga excessiva de exercício físico, muitos adolescentes comem menos calorias do que necessitam, o que pode trazer vários comprometimentos à saúde.

Divulgar cardápio sem levar em consideração todos os aspectos que envolvem o comportamento alimentar do indivíduo, além de ser um cardápio para emagrecimento rápido, é uma prática totalmente discutível para a ciência da nutrição. Em relação à rapidez para emagrecer, considera-se que há uma adaptação do organismo (metabolismo) às novas quantidades de alimento e que essa adaptação deve ser lenta, pois é um processo de mudança, de reeducação alimentar. Portanto, se a perda de peso for rápida, da mesma forma o indivíduo recupera o peso perdido, é o famoso "efeito sanfona".

Em relação aos pontos convergentes entre os discursos da revista sobre práticas alimentares para emagrecimento e os discursos sobre as mesmas práticas na ciência da nutrição, selecionamos al guns exemplos: Quando você proíbe um alimento numa dieta, a tendência é que a pessoa, quando não consegue se conter, se sinta impotente. Ela acha que fracassou e fica uma sensação de angústia, o que leva a compensar o sofrimento com mais comida, explica (endocrinologista, revista Capricho, 19 de dezembro de 1999); Não caia na tentação de se automedicar. Qualquer tipo de medicamento provoca efeitos colaterais (endocrinologista, revista Capricho, 25 de abril de 1999); ....além disso, cada pessoa tem um metabolismo diferente, que leva mais ou menos tempo para queimar energia (nutricionista, revista Capricho, 25 de abril de 1999).

Para a ciência da nutrição não devemos privar os indivíduos de comer aquilo de que gostam, pois sabemos que 0 ato de comer também é um ato de prazer. 0 ideal é escolher junto ao cliente os al imentos que mais Ihe apetecem e encontrar formas ou técnicas de preparo que os tornem mais saborosos enutritivos.

Consideramos que a proibição não é o meIhor caminho, pois a pessoa se sentirá frustrada e, por conseguinte, abandonará a dieta. 0 conhecimento do alimento e de si próprio, ou seja, a conscientização da importância da alimentação em todos os aspectos que envolvem a boa saúde é fundamental. Portanto, a nutrição apóia-se no processo educacional, que muitas vezes é lento, porém, eficaz, pois passa a ser o estilo da pessoa se alimentar, que é próprio e não imposto.

Uma alimentação equilibrada quantitativa e qualitativamente, aliada a uma prática desportiva, garante o trabal ho metabólico normal, que conduz 0 indivíduo a atingir e manter seu peso ideal. Enfim, a alimentação saudável e equilibrada dispensa o uso de medicamentos.

\section{Considerações finais e recomendações}

H ábitos e práticas alimentares são construídos com base em determinações socioculturais. No mundo contemporâneo, a mídia desempenha papel estruturador na construção e desconstrução de procedimentos alimentares.

As práticas alimentares de emagrecimento inserem-se numa lógica de mercado impregnada por um padrão estético de corpo ideal. A indústria cultural move-se articulando diferentes campos, como empresas produtoras de mercadorias, indústrias de aparel hos e equipamentos e setores financeiros. É nessa dessa lógica que se produzem os paradigmas estéticos e, por conseqüência, discursos sobre práticas alimentares para emagrecimento.

Palavras, textos e imagens constituem uma intricada rede de relações que imbricam história e tecnologia num domínio específico que produz poder. 0 discurso científico funciona mediante regras preestabel ecidas em determinadas condições de produção e é, assim, representação de poder e de controle social. 0 discurso midiático se transveste como síntese desses discursos científicos, mas apenas generalizante e os reelabora de forma descontextualizada e destituída de sua identidade.

A análise dos sentidos e significados presentes nos títulos das matérias da maior revista voltada para o público feminino adolescente mostra que o empenho em seduzir está presente na maior parte deles. Os títulos das matérias da revista Capricho não escondem significados ou sentidos, são claros e diretos por ser uma revista direcionada ao público adolescente, que se identifica mais com a linguagem imagética, que apresenta pouco texto, exige pouca leitura e oferece muita informação rápida/instantânea. 
Os discursos das matérias da revista sobre práticas alimentares para emagrecimento aparecem sempre proferidos por especialistas, artistas e adolescentes, atores sociais que, em razão de sua especificidade, encerram a sua participação como formadores de opinião, comportamentos e estilos.

No discurso dos especialistas existe um julgamento daquilo que é considerado acerto ou erro de uma abordagem científica. Tais discursos se mostram a partir de um referente técnico, evocando a ciência como forma de criar vínculos socioculturais e legitimar as informações vei culadas. Já os discursos dos artistas, a força do "dito" está nas imagens. Os significados e sentidos subjacentes a esses discursos são a fama, o sucesso, o poder, e a cultura narcísea e individualista da pós-modernidade.

Os discursos dos adolescentes representam o senso comum. Neles observamos a imbricação dos diversos saberes articulados contribuindo para a formação de um saber comum a todos. É, porém, um saber frágil, inconsistente, uma vez que reflete o conflito criado pelos diferentes interesses dos diversos saberes. É o discurso dos que se expressam por aquilo que ouvem, sem ter um filtro ou canal para questionar se o que está recebendo como informação ébom ou ruim para eles.

A intermediação dos discursos é feita pelos repórteres e nela estão presentes de forma implícita ou explícita os interesses do discurso midiático. Nas matérias sobre práticas alimentares para emagrecimento, constatamos os interesses das indústrias ligadas ao corpo e, por

\section{Referências bibliográficas}

Benveniste E 1989. Problemas de lingüística geral II. Pontes, Campinas.

Braga WD 1999. Ciência e mídia: a legitimação de um mito perigoso. Publicação da Pós-Graduação em Comunicação e Cultura da Escola de Comunicação, UFRJ.

Focault M 1999 (1971). (5a ed.). A ordem do discurso. Edições Loyola. São Paulo.

Gambardella AMD 1999. Práticas alimentares de adolescentes. Revista de Nutrição 1:55-59, PUC Campinas

Lopes PFC 1998. Corpos (em) cena: a construção do discurso midiático sobre a noção de saúde e de risco a quatro anos do século XXI. Dissertação de mestrado, Escola de Comunicação, UFRJ.

Pinto MJ 1999. Comunicação e discurso. Hacker Editores, São Paulo.

Porto SD 1997. A esquerda esquecida de Fernando Henrique Cardoso: um método, pp. 363-380. In M conseguinte, a divulgação de um padrão estético corporal determinado é "quase imposição" por parte dos textos da intermediação.

Quanto às modalidades discursivas da mídia, encontramos mais modalidades divergentes daquilo que é preconizado pela ciência da nutrição.

O conteúdo do discurso da mídia, especificamente o da revista Capricho, mostra-se de cunho informativo, mas nem sempre pode ser tomado como base. 0 fato de ser informativo não significa que seja adequado, científico, saudável. 0 discurso midiático é ambíguo e pode ser capcioso. A informação, no caso, não representa, necessariamente, a "verdade", não é educativa nem formadora e não cria alicerces sólidos para o indivíduo.

O profissional de saúde enutrição não pode estar alheio ao que se passa no mercado midiático, particularmente em se tratando de adolescentes, sob o risco de incorrer numa alienação e num afastamento do público/cliente a quem atende. De nada adianta prescrever dietas, divulgar práticas alimentares saudáveis descontextualizadas da forte influência que esse público recebe da mídia.

Para efeito de conclusão, ressaltamos a importância da dimensão educativa dos profissionais de saúde e nutrição para o público adolescente, particularmente do sexo feminino. Informar e orientar adolescentes em relação aos seus hábitos alimentares é um desafio que se impõe àqueles que acreditam que o corpo pode e deve ser pensado em suas múltiplas dimensões, não se restringindo a padrões modulares estéticos.
Mouillaud \& SD Porto (orgs.). O jornal - da forma ao sentido. Paralelo 15, Brasília.

Rotenberg S 1999. Práticas alimentares e o cuidado da saúde da criança de baixo peso. Dissertação de mestrado. Instituto Fernandes Figueiras, Fiocruz, Rio de Janeiro.

Serra GM A 2001. Saúde e nutrição na adolescência: o discurso sobre dietas na revista Capricho. Escola Nacional de Saúde Pública, Fiocruz, Rio de Janeiro.

Véron E 1983. Quand lire c'est faire: I' enonciation dans le discours de la presse écrite. In Sémiotique II. IREP, Paris

Artigo apresentado em 12/6/2003

Aprovado em 29/6/2003

Versão final apresentada em 14/7/2003 